\title{
Activated Self-Resolution and Error-Correction in Catalytic Reaction Networks
}

\author{
Fredrik Schaufelberger ${ }^{[\mathrm{a}]}$ and Olof Ramström*[a],[b],[c] \\ ${ }^{a}$ Department of Chemistry, KTH - Royal Institute of Technology, Teknikringen 36, S-10044 Stockholm, Sweden; ${ }^{b}$ Department \\ of Chemistry, University of Massachusetts Lowell, One University Ave., Lowell, MA 01854, USA; \\ Email: olof ramstrom@uml.edu; ' ${ }^{c}$ Department of Chemistry and Biomedical Sciences, Linnaeus University, SE-39182 \\ Kalmar, Sweden
}

\begin{abstract}
To understand the emergence of function in complex reaction networks is a primary goal of systems chemistry and origin-of-life studies. Especially challenging is the establishment of systems that simultaneously exhibit several functionality parameters that can be independently tuned. In this work, a multifunctional complex reaction network of nucleophilic small molecule catalysts for the Morita-Baylis-Hillman (MBH) reaction is demonstrated. The dynamic system exhibited triggered self-resolution, preferentially amplifying a specific catalyst/product set out of a many potential alternatives. By utilizing selective reversibility of the products of the reaction set, systemic thermodynamically driven error-correction could also be introduced. To achieve this, a dynamic covalent $\mathrm{MBH}$ reaction based on adducts with internal H-transfer capabilities was developed, displaying rate accelerations of retro-MBH reactions up to $10^{4}$ times. This study demonstrates how efficient self-sorting of catalytic systems can be achieved through an interplay of several complex emergent functionalities.
\end{abstract}

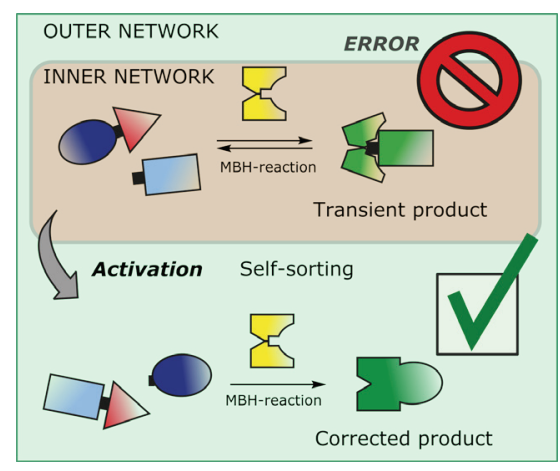

\section{INTRODUCTION}

Biological systems are based on complex networks of interconnected chemical interactions and reactions. All these biochemical processes operate in concert to provide advanced emergent properties such as replication, regulation and self-organization. ${ }^{[1]}$ Eventually, when a certain level of connectedness in reaction networks is reached, self-conscious living systems may arise. To understand Nature's complex machinery and how it may have emerged, synthetic systems can be used to mimic biotic reaction networks. ${ }^{[2-4]}$ By studying the systems chemistry of small molecule models, important insights into emergence of life-like behavior in prebiotic settings can be achieved. ${ }^{[5]}$

Significant advances in the design of synthetic systems capable of, for example, selfreplication, ${ }^{[2,6-8]}$ self-organization, ${ }^{[9-11]}$ self-sorting, ${ }^{[12-14]}$ and compartmentalization, ${ }^{[15,16]}$ have all been made in recent years. One area of systems chemistry that has received particular 
attention is emergent catalytic and autocatalytic behavior, since catalysis is perceived to be a crucial component in virtually all origin-of-life models. ${ }^{[17-21]}$ However, the systems chemistry of adaptive catalytic molecules is still poorly understood. We have previously investigated reaction networks of so-called dynamic covalent catalysts. ${ }^{[22-26]}$ By connecting catalytically active components with reversible imine bonds (Figure 1a), catalysts capable of modifying their own molecular architecture are accessible. When incorporated into dynamic systems undergoing constitutional exchange, these compounds display self-resolving behavior. This means that the constituents act on the system of which they are part, which drives evolution of new networks of increasing or decreasing complexity. ${ }^{[27-32]}$

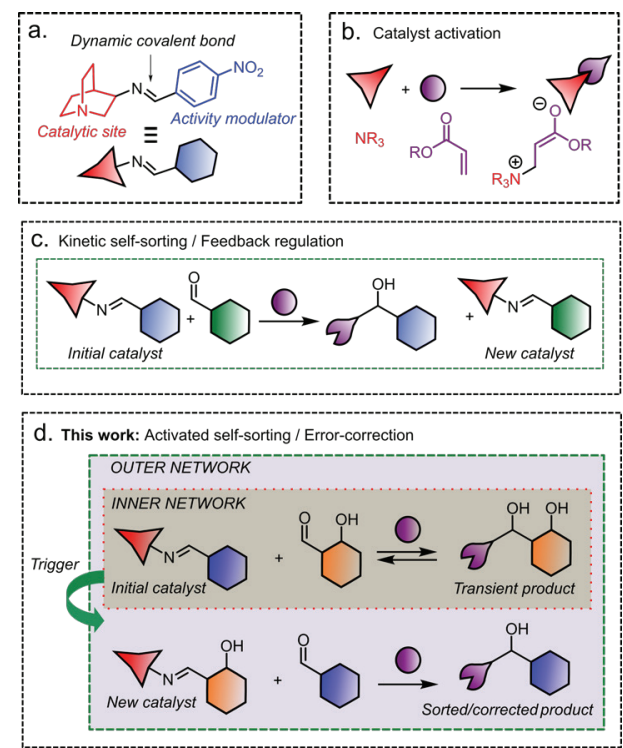

Figure 1: a) Schematic representation and molecular architecture of dynamic covalent catalyst class used. b) Tertiary amine activation of acrylates for nucleophilic attack. c) Outline of previous study:[25] a reactant/catalyst set rearranges to a product/new catalyst set during the course of the catalytic event. d) Outline of the current study: a dynamic covalent MBH reaction enables the catalyst system to perform error-correction of the product/catalyst set.

A transformation that has proven highly useful as a model system in these studies is the Morita-Baylis-Hillman (MBH) reaction, which is enabled through nucleophilic catalysis (Figure 1b). ${ }^{[25]}$ By using a dynamic iminoquinuclidine catalyst ${ }^{[33]}$ for the $\mathrm{MBH}$ reaction and tuning the conditions so that self-resolution was performed under kinetic control, a secondary function in the form of feedback regulation emerged (Figure 1c). ${ }^{[25]}$ Since the formation of product and a new catalyst architecture was coupled, the exchange process always tuned the catalyst activity as a response to the catalytic event.

During these studies, some important insights regarding the complex mechanism of the MBH reaction were gained. ${ }^{[34-42]}$ It was thus clear that the MBH reaction was under kinetic control in the time regimes investigated. However, some substrates showed clear signs of transient product formation of an "erroneous" $\mathrm{MBH}$ product, which subsequently decayed back into the starting materials during the self-resolution. This led to the hypothesis that errorcorrection behavior can be programmed into the systems through incorporation of conditional reversibility in the product. The systems were then envisaged to initially undergo transformation towards a transient product, resulting in an $\mathrm{MBH}$ adduct/catalyst set imposed by these conditions (Figure 1d, inner network, red striped zone). Primed for the retro-reaction, a secondary self-sorting process could then subsequently traject the components away from this state towards the most stable MBH adduct/catalyst set (Figure 1d, outer network, green 
lined area). A systemic expansion, from an isolated state towards a complete network, could thus be unlocked by a single input (addition of acid to turn on imine exchange).

Key to the realization of this behavior is creation of conditionally reversible product forming reactions. The $\mathrm{MBH}$ reaction has long been considered attractive for use in dynamic covalent chemistry. ${ }^{[43-46]}$ It is a self-contained transformation under complete catalyst control, and it is known that the reaction show some temperature-dependent reversible character. ${ }^{[37]}$ However, the equilibration rates have generally been far too low for use in dynamic systems. ${ }^{[47,48]}$ Herein, we disclose that internal proton transfer within MBH adducts results in highly accelerated reversible reactions that make the $\mathrm{MBH}$ reaction suitable for use in dynamic covalent chemistry. Furthermore, these results were used to realize dynamic catalyst systems with multiple emergent functionalities. ${ }^{[49,50]}$ We demonstrate how the reversible $\mathrm{MBH}$ reaction along with integral catalysis can be used to create activated reaction networks capable of two parallel functions: systemic self-sorting and programmable errorcorrection. Finally, we show how all these design elements come together to form expanded networks where self-sorting from large systems of constituents into just a single new product can be observed.

\section{RESULTS AND DISCUSSION}

\section{Dynamic Covalent MBH Reactions}

To understand how error-correcting catalytic systems can be created, a detailed understanding of the reversibility of the MBH adducts in our previous study was first targeted. ${ }^{[25]}$ It quickly became clear during preliminary investigations that salicylaldehydes exhibited unusual MBH equilibration rates (Table 1). ${ }^{[51,52]}$ This class of compounds rapidly gave rise to $\mathrm{MBH}$ adducts under thermodynamic control, in contrast to almost all other substrates tested.

To confirm these findings, a range of substituted $\mathrm{MBH}$ adducts were synthesized and subjected to retro-MBH conditions using the general nucleophilic catalyst DABCO. ${ }^{[53]}$ In order to suppress the cyclization reactions observed by Kaye, [54] tert-butyl or adamantylacrylates had to be used (Table S1). Using these, a large acceleration in fragmentation rate with salicylaldehyde-derived adduct $\mathbf{2 b}$, compared to $p$-nitro-substituted reference compound 2a, (Table 1, entries 1-2) was noticed. The effect was even more pronounced upon substitution of the tert-butyl moiety for an adamantyl group (Table 1, entry $3)$.

Both electron-rich and electron-poor $o$-hydroxy-substituted $\mathrm{MBH}$ adducts $2 \mathbf{d}$ and $\mathbf{2 e}$ (Table 1, entries 4-5) exhibited high retro-reaction rates, indicating that electronic effects is not the primary factor facilitating reversibility. Substrate $\mathbf{2} \mathbf{f}$ contains an amide in the orthoposition of the aromatic ring to the allylic alcohol (Table 1, entry 6). It was hypothesized that if internal proton transfer was responsible for the rate acceleration, this compound should also exhibit enhanced retro-MBH rates compared to substrate 2a. This was indeed observed, although to a diminished degree compared to salicylaldehyde-derived substrates due to the low acidity of the amide group. Further evidence for the proton transfer hypothesis was obtained with $m$-hydroxy-substituted adduct $\mathbf{2 g}$, which did not show any acceleration compared to the reference (Table 1, entry 7). This indicates negligible contributions from intermolecular hydrogen bonding or intermolecular proton shuttling. Similarly, nonH-bonding compounds $\mathbf{2 h}$ and $\mathbf{2 i}$ also showed lower retro-MBH reaction rates (Table 1, entries 8-9). The rate for $o$-methoxy-substituted adduct $\mathbf{2 i}$ is especially noteworthy, as substitution of the phenolic hydrogen for a methyl group led to a 7000-fold rate deceleration. 
Table 1. Kinetics and thermodynamics of retro-MBH reactions with different substitution patterns. [a]

\begin{tabular}{|c|c|c|c|c|}
\hline Entry & Substrate & $v_{0}(\mathrm{mM} / \mathrm{min})^{[\mathrm{b}]}$ & Relative rate & $K(\mathbf{M})^{[\mathbf{c}]}$ \\
\hline 1 & & $6.4 \times 10^{-4}$ & 1.0 & 0.0033 \\
\hline 2 & & $1.5 \times 10^{-1}$ & 232 & 1.84 \\
\hline 3 & & $1.9 \times 10^{-1}$ & 301 & 1.62 \\
\hline 4 & & $7.8 \times 10^{-2}$ & 123 & 0.96 \\
\hline 5 & & $5.1 \times 10^{-2}$ & 80 & {$[\mathrm{~d}]$} \\
\hline 6 & & $8.7 \times 10^{-3}$ & 14 & 0.37 \\
\hline 7 & & $7.1 \times 10^{-4}$ & 1.1 & 0.19 \\
\hline 8 & & $2.2 \times 10^{-4}$ & 0.35 & $-[\mathrm{d}]$ \\
\hline 9 & & $2.2 \times 10^{-5}$ & 0.034 & {$[\mathrm{e}]$} \\
\hline
\end{tabular}

[a] Conditions: MBH adduct $(0.1 \mathrm{mmol}), \mathrm{DABCO}(0.1 \mathrm{mmol}), \mathrm{MeCN}-d_{3}(0.50 \mathrm{~mL}), \mathrm{rt}, \mathrm{N}_{2} .{ }^{[\mathrm{b}]}$ Initial rate over first $5-12 \%$ of

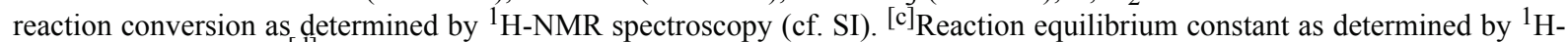
NMR spectroscopy. [d] Long-term stability of aldehyde poor, equilibrium not reached before partial decomposition. ${ }^{[\mathrm{e}]}$ Equilibrium not reached due to slow kinetics.

The position of the equilibrium at room temperature could be recorded for some reactions, for which the time to reach thermodynamic equilibria varied from $24 \mathrm{~h}$ (compounds $\mathbf{2 b}$ and $\mathbf{2 c}$ ) to five months (compound $\mathbf{2 g}$ ). In line with previous observations, electron-poor aryl aldehydes favored the $\mathrm{MBH}$ adduct, whereas electron-rich aryl aldehydes preferred the aldehyde/acrylate side. ${ }^{[26]}$ Dual entry-point analysis with compound $\mathbf{2 b}$ was used to confirm the thermodynamic nature of the equilibrium, and similar product distributions were reached in $72 \mathrm{~h}$ (cf. Scheme S1).

To study the origin of the rate acceleration with H-bonding substrates, the energyminimized conformation of $\mathbf{2} \mathbf{b}$ was calculated (DFT) showing the presence of a coupled $\mathrm{H}$-bond system (Figure 2a). This type of polarization-enhanced $\mathrm{H}$-bonding can contribute to $\mathrm{H}$-bond donor strength by orders of magnitude, ${ }^{[55,56]}$ potentially activating the acrylate fragment and accelerating the nucleophilic attack on compound $\mathbf{2 b}$. The phenolic orthosubstitution pattern may potentially also facilitate the proton transfer step preceding the elimination of the nucleophile (Figure 2 b). 

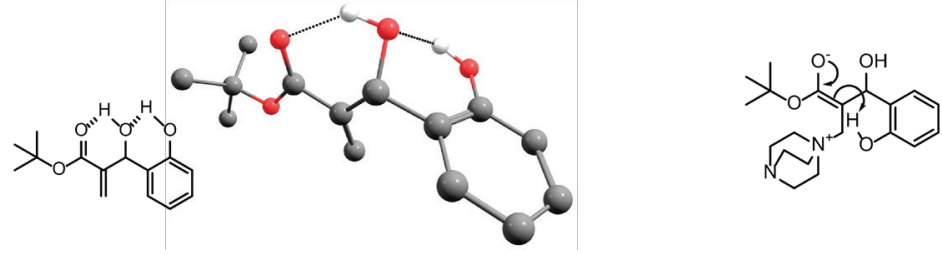

Figure 2: a) Optimized conformation of compound $2 \boldsymbol{b}$ (DFT, B3LYP/6-31G(d)). Non H-bonding hydrogens omitted for clarity. b) Potential retro-MBH rate acceleration via internal proton transfer (six-membered TS).

Further insights into the reaction mechanism of the $\mathrm{MBH}$ reaction was obtained by measuring the initial fragmentation rates of compound $\mathbf{2 b}$ in the presence of DABCO over a range of concentrations (Figure S1). A linear response was observed for compound $\mathbf{2 b}$, with approximate first order concentration dependence. For the nucleophilic catalyst, saturation kinetics with a maximum rate at ca 1.0 equiv. was recorded. Approximate first order dependence was in this case observed at lower concentrations, indicating that the initial nucleophilic attack is reversible and not rate-limiting. This corroborates earlier reports regarding $\mathrm{MBH}$ systems with protic additives, which suggested the proton transfer step to be rate-determining. [39]

Taken together, these results provide a clear roadmap for creating dynamic covalent MBH reactions, where internal $\mathrm{H}$-transfer is a crucial component to enable rapid equilibration.

\section{Error-Correcting Reaction Networks}

Equipped with an enhanced understanding of the systems, the H-bond-assisted MBH reaction was next applied to activated self-sorting catalytic networks, and a system was set up as shown in Figure 3 . Salicylaldehyde-derived MBH adduct $\mathbf{2 b}$ was first mixed with catalyst $\mathbf{C 1}$ (Figure $\underline{3}$, orange-shaded Path A, cf. also Schemes S1 and S3). This led to the fragmentation of adduct $\mathbf{2} \mathbf{b}$ into tert-butyl acrylate and salicylaldehyde $\mathbf{1 b}$, catalyzed by compound $\mathbf{C 1}$, with an equilibrium being established within $48 \mathrm{~h}$ (Table 1 , entry 2). ${ }^{[57]}$

However, upon addition of a system activator/trigger, benzoic acid, a complex retro$\mathrm{MBH} /$ imine exchange/MBH reaction cascade was turned-on (Figure $\underline{3}$, green-shaded Path $\mathrm{B}$ ). $\mathrm{MBH}$ adduct 2a was thus formed along with an equivalent amount of new catalyst $\mathbf{C 2}$, indicating that the system still maintained the products and catalysts paired in equimolar sets. This led to gradual downregulation of catalyst $\mathbf{C 1}$, concomitant with a decrease in $\mathrm{MBH}$ adduct $\mathbf{2 b}$, while accelerating the formation of adduct $\mathbf{2 a}$. To monitor the process, a system was set up with catalyst $\mathbf{C 1}$ and aldehyde $\mathbf{1 b}$. When benzoic acid and tert-butyl acrylate were added, compound $\mathbf{C 1}$ initially catalyzed the $\mathrm{MBH}$ reaction between the free aldehyde $\mathbf{1 b}$ and the acrylate to give $\mathrm{MBH}$ adduct $\mathbf{2 b}$ (Figure $\underline{4}$, circles). As the reaction progressed, imine exchange between the compound pairs $\mathbf{C 1 / 1 b}$ and $\mathbf{C 2} / \mathbf{1 a}$ occurred producing the more reactive aldehyde $\mathbf{1 a}$ and the more stable $\mathrm{MBH}$ adduct $\mathbf{2 a}$. 


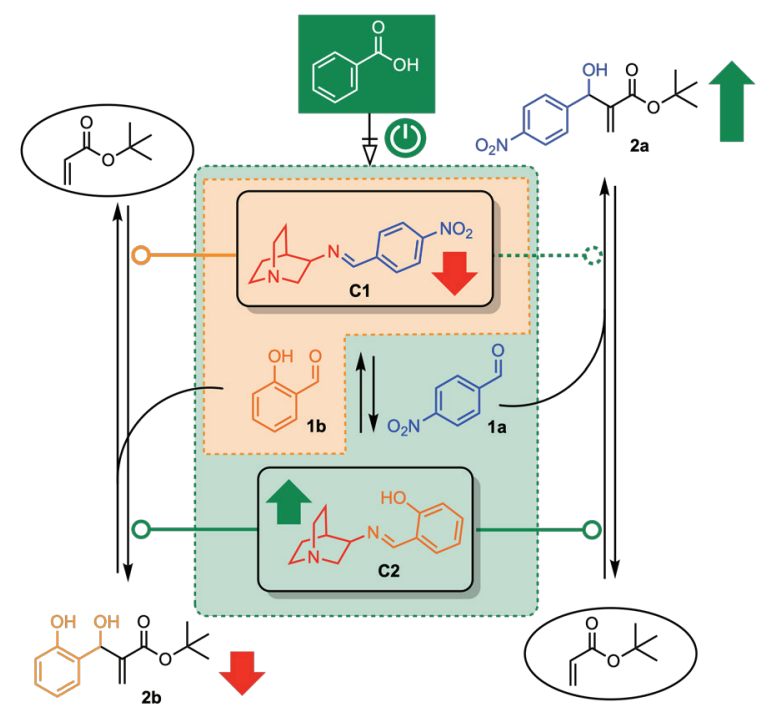

Figure 3: Activated self-sorting and error-correcting dynamic reaction network. Inner network (orange-shaded): network consisting of catalyst $\mathbf{C 1}$ and $\mathrm{MBH}$ adduct $\mathbf{2 b}$. Outer network (green-shaded): Addition of trigger, benzoic acid, leading to turn-on of imine exchange and formation of catalyst $\boldsymbol{C} 2$ and aldehyde 1a. This led to downregulation of catalyst $\boldsymbol{C 1}$ and adduct $\mathbf{2 b}$, while accelerating the formation of MBH adduct $\mathbf{2 a}$. Symbols: — catalysis; $+>$ activation.

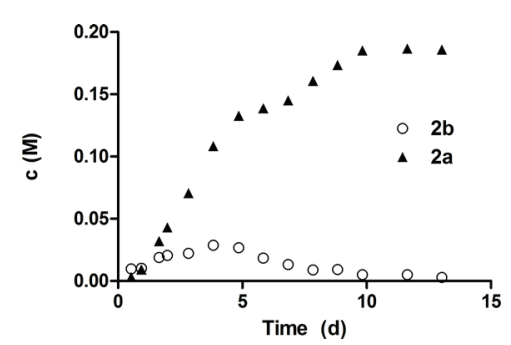

Figure 4: Conversion measured by ${ }^{1} H$ NMR integration of the key aromatic and alkene signals with internal standard. Conditions: catalyst $\mathbf{C 1}(0.1 \mathrm{mmol})$, aldehyde $\mathbf{1 b},(0.1 \mathrm{mmol}), \mathrm{PhCOOH}(0.1 \mathrm{mmol})$, tert-butyl acrylate (1.0 mmol), $\mathrm{MeCN}(0.5 \mathrm{~mL}), 40^{\circ} \mathrm{C}, \mathrm{N}_{2}$.

As can be seen from Figure $\underline{4}$, an initial buildup of the kinetic product $\mathbf{2 b}$ was observed but the concentration eventually decreased until the compound essentially disappeared from the system (cf. Figure S4). In contrast, the generation of adduct 2a was initially slow due to the low amounts of compound 1a available in solution during the early phase of the reaction. As the imine equilibrium was gradually established over several days, MBH adduct $\mathbf{2 a}$ started to form in larger amounts (Figure $\underline{4}$, triangles) while adduct $\mathbf{2 b}$ was being consumed via the retro-MBH reaction. The final system composition was composed of $93 \%$ of adduct $2 \mathbf{a}$ and $7 \%$ of aldehyde $\mathbf{1 b}$, reached after ca $14 \mathrm{~d}$. From the distinct kinetic profile, the errorcorrection regime is evident between 4-10 d. The evolution of compound 2a reached a plateau after $4 \mathrm{~d}$, which closely mirrored the point where a maximum concentration of $\mathbf{2 b}$ was reached.

Thus, the system exhibited activated thermodynamically-driven error-correction with selfsorting towards the MBH adduct $\mathbf{2 a}$ and the connected catalyst $\mathbf{C 2}$. The role of the trigger species (benzoic acid) in the system was crucial. In the absence of this catalyst, the expansion of the network was hindered and only a simple MBH reaction equilibrium was obtained. This mode of self-resolution provides an additional systemic mechanism for complexity evolution, providing another step on the road towards the grand goal of systems chemistry to developing dynamic catalytic systems that simulates the functionality of metabolic and regulatory 
biochemical pathways.

\section{Expanded Self-Sorting Systems}

With an enhanced set of design rules established, the potential of generating expanded systems capable of activated self-sorting from larger compound pools was next addressed (Figure 5). Naturally, the self-sorting efficiency in such scenarios always decreases due to the lower concentrations of the active species, and hence it is of great interest to probe the limits of the self-resolution procedure.

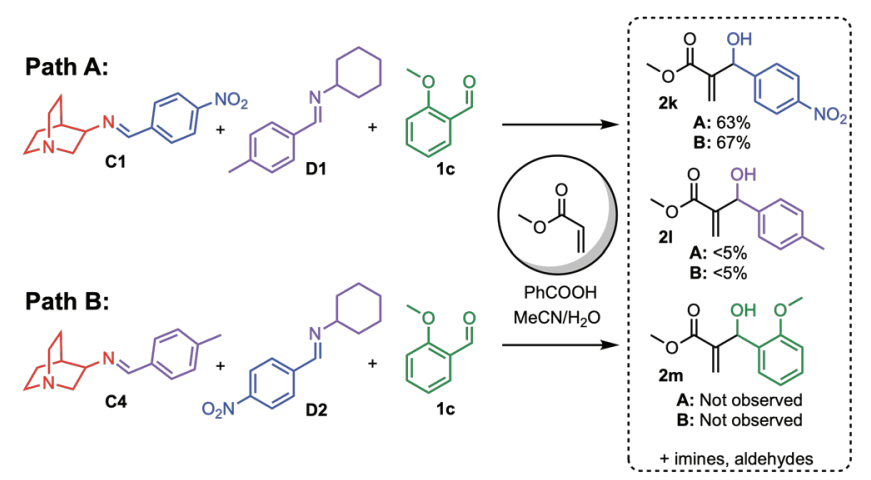

Figure 5: Expanded self-sorting systems under kinetic control. Conditions: catalyst C1/C4 (0.04 mmol), imine D1/D2 (0.04 mmol), aldehyde $1 \mathrm{c},(0.04 \mathrm{mmol}), \mathrm{PhCOOH}(0.04 \mathrm{mmol})$, methyl acrylate $(0.4 \mathrm{mmol}), \mathrm{MeCN} / \mathrm{H}_{2} \mathrm{O}$ (99:1, $0.2 \mathrm{~mL}), r t, N_{2}$.

To introduce new aldehyde components to the system without risking unselective MBH reactions under kinetic control, the new aldehyde substrates were "masked" as imines with cyclohexylamine. Initially, kinetic self-sorting along the lines of Figure 1c was attempted with imines D1 and D2 added to the systems along with the previously employed electron-rich aldehyde 1c (Figure 5). ${ }^{[25]}$ Upon addition of acid, these compounds all participated in the dynamic imine system, resulting in rapidly increased complexity with several new aldehyde and imine species observed during the reaction.

Table 2. Self-sorting efficiency in expanded dynamic catalyst systems. ${ }^{[a]}$

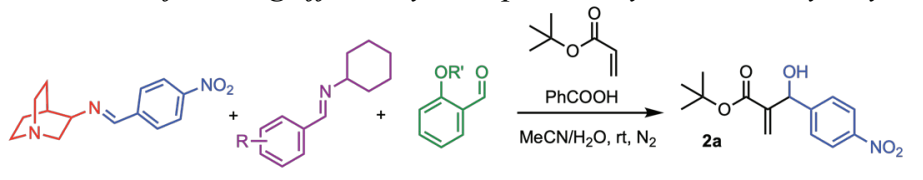

$\begin{array}{lllll}\text { C1 } & \text { D3 } & \mathrm{R}=2-\mathrm{NMe}_{2} & \text { 1b } & \mathrm{R}^{\prime}=\mathrm{H} \\ \mathrm{D} 4 & \mathrm{R}=2-\mathrm{OH}, 3-\mathrm{OMe} & 1 \mathrm{c} & \mathrm{R}^{\prime}=\mathrm{Me}\end{array}$

\begin{tabular}{cccc}
\hline Entry & Imine(s) & Aldehyde & Yield 2a (\%) \\
\hline 1 & D3 & 1c & 51 \\
2 & D3 & 1b & 57 \\
3 & D4 & 1c & 72 \\
4 & D4 & 1b & 91 \\
5 & D3, D4 & $\mathbf{1 c}$ & 32 \\
6 & D3, D4 & 1b & 42 \\
\hline
\end{tabular}

[a]Conditions: catalyst C1 $(0.04 \mathrm{mmol})$, imine D3/D4 $(0.04 \mathrm{mmol}$ each), aldehyde 1b/1c, $(0.04 \mathrm{mmol}), \mathrm{PhCOOH}$ $(0.04 \mathrm{mmol})$, tert-butyl acrylate $(0.4 \mathrm{mmol}), \mathrm{MeCN} / \mathrm{H}_{2} \mathrm{O}(99: 1,0.2 \mathrm{~mL}), \mathrm{rt}, \mathrm{N}_{2}, 10 \mathrm{~d}$.

Regardless of the starting position and number of components, aldehyde 1a was however always selected as the coupling partner from the systems (compare output from Path A and B in dashed box, Figure $\underline{5}$ ).

The MBH reaction networks could also be expanded to up to twelve potential electrophiles 
by addition of two new cyclohexylamine-derived imines D3 and D4 (Table 2). The system self-sorted efficiently both with the error-correcting substrate $\mathbf{1 b}$ and non-correcting $\mathbf{1 c}$ (Table 2). In all cases, the system showed complete chemoselectivity for aldehydes over $\mathrm{N}$-alkyl imines, exclusively selecting the most electron-poor aryl aldehyde 1a as the $\mathrm{MBH}$ coupling partner. No side-products or other $\mathrm{MBH}$ adducts were ever observed from the system. The self-sorting could also reach efficiencies over $90 \%$ yield (Table 2 , entry 4 ), but slowed down considerably with increased number of compounds (Table 2, entries 5 and 6). Nevertheless, this strategy clearly enables the construction of more complex and sophisticated self-sorting systems.

\section{CONCLUSIONS}

In summary, we have demonstrated that imine exchange and reversible MBH reactions can be coupled to self-resolving catalysts, providing dynamic catalytic systems capable of errorcorrection. We have furthermore investigated how internal proton transfer may activate MBH adducts to achieve high reversibility, which now enables this attractive, self-contained C-C bond forming reaction to be applied in dynamic covalent chemistry.

Finally, this chemistry has been applied to activated self-sorting of dynamic catalysts in both small and expanded dynamic systems with good efficiencies. These reaction networks are unique in that the generation of a product set is accompanied by the creation of an associated new catalyst, and the systems furthermore error-correct for the catalyst composition that leads to its own creation. Hence, through a judicious choice of parameters, these systems potentially enable programmed loops and novel autocatalytic and systemic behavior that is reliant on the error-correction mechanism.

\section{ACKNOWLEDGEMENTS}

This study was in part supported by the Swedish Research Council. FS thanks KTH for an Excellence Award. Björn Dahlgren is gratefully acknowledged for assistance with the DFT calculations.

Keywords: Dynamic Chemistry, Imine Exchange, Hydrogen Bonding Catalysis, Dynamic Systems, Solid-Supported Catalyst

\section{REFERENCES}

[1] G. M. Whitesides, R. F. Ismagilov, Science 1999, 284, 89-92.

[2] T. Kosikova, D. Philp, Chem. Soc. Rev. 2017, 46, 7274-7305.

[3] O. Š. Miljanić, Chem 2017, 2, 502-524.

[4] J.-M. Lehn, Angew. Chem. Int. Ed. 2015, 54, 3276-3289.

[5] K. Ruiz-Mirazo, C. Briones, A. de la Escosura, Chem. Rev. 2013, 114, 285-366.

[6] G. Clixby, L. Twyman, Org. Biomol. Chem. 2016, 14, 4170-4184.

[7] Z. Dadon, N. Wagner, S. Alasibi, M. Samiappan, R. Mukherjee, G. Ashkenasy, Chem. Eur. J. 2015, 21, 648-654.

[8] R. Nguyen, L. Allouche, E. Buhler, N. Giuseppone, Angew. Chem. Int. Ed. 2009, 48, 1093-6.

[9] Y. Zhang, C. T. Supuran, M. Barboiu, Chem. Eur. J. 2018, 24, 715-720.

[10] P. Solis Munana, G. Ragazzon, J. Dupont, C. Z. Ren, L. J. Prins, J. L. Chen, Angew. Chem. Int. Ed. 2018, $57,16469-16474$.

[11] O. Shyshov, R.-C. Brachvogel, T. Bachmann, R. Srikantharajah, D. Segets, F. Hampel, R. Puchta, M. von Delius, Angew. Chem. Int. Ed. 2017, 56, 776-781. 
[12] A. G. Orrillo, A. M. Escalante, M. Martinez-Amezaga, I. Cabezudo, R. L. E. Furlan, Chem. Eur. J. 2019, $25,1118-1127$.

[13] Z. He, W. Jiang, C. A. Schalley, Chem. Soc. Rev. 2015, 44, 779-789.

[14] Q. Ji, R. C. Lirag, O. S. Miljanic, Chem. Soc. Rev. 2014, 43, 1873-1884.

[15] A. G. Salles, S. Zarra, R. M. Turner, J. R. Nitschke, J. Am. Chem. Soc. 2013, 135, 19143-19146.

[16] Z. J. Wang, K. N. Clary, R. G. Bergman, K. N. Raymond, F. D. Toste, Nat. Chem. 2013, 5, 100-103.

[17] A. Mariani, J. D. Sutherland, Angew. Chem. Int. Ed. 2017, 56, 6563-6566.

[18] S. N. Semenov, L. J. Kraft, A. Ainla, M. Zhao, M. Baghbanzadeh, V. E. Campbell, K. Kang, J. M. Fox, G. M. Whitesides, Nature 2016, 537, 656-660.

[19] P. Kovaricek, A. C. Meister, K. Flidrova, R. Cabot, K. Kovarickova, J. M. Lehn, Chem. Sci. 2016, 7 , 3215-3226.

[20] M. Tena-Solsona, J. Nanda, S. Díaz-Oltra, A. Chotera, G. Ashkenasy, B. Escuder, Chem. Eur. J. 2016, 22 , 6687-6694.

[21] H. Fanlo-Virgós, A.-N. R. Alba, S. Hamieh, M. Colomb-Delsuc, S. Otto, Angew. Chem. Int. Ed. 2014, 53, $11346-11350$.

[22] Since the dynamic covalent catalysts change their molecular architecture during the catalytic events, theyare not "catalytic" as per the common IUPAC definition (unlike DABCO or benzoic acid used elsewhere in this work, whichact as catalysts in the traditional sense). Still, thecatalytically active site (the quinuclidine moiety) is regenerated at the end of the reaction and thus the total amount of the catalytically active quinuclidine units in the system remains constant during the experiments.

[23] A. Serra-Pont, I. Alfonso, J. Sola, C. Jimeno, Chem. Commun. 2019, 55, 7970-7973.

[24] V. Dhayalan, S. C. Gadekar, Z. Alassad, A. Milo, Nat. Chem. 2019, 11, 543-551.

[25] F. Schaufelberger, O. Ramström, J. Am. Chem. Soc. 2016, 138, 7836-7839.

[26] F. Schaufelberger, O. Ramström, Chem. Eur. J. 2015, 21, 12735-12740.

[27] M. Kołodziejski, A. R. Stefankiewicz, J.-M. Lehn, Chem. Sci. 2019, 10, 1836-1843.

[28] L. Hu, Y. Zhang, O. Ramström, Sci. Rep. 2015, 5, 11065.

[29] R. C. Lirag, K. Osowska, O. S. Miljanic, Org. Biomol. Chem. 2012, 10, 4847-4850.

[30] M. Angelin, P. Vongvilai, A. Fischer, O. Ramström, Eur. J. Org. Chem. 2010, 2010, 6315-6318.

[31] P. Vongvilai, O. Ramström, J. Am. Chem. Soc. 2009, 131, 14419-14425.

[32] F. Schaufelberger, B. J. J. Timmer, O. Ramström, Chem. Eur. J. 2018, 24, 101-104.

[33] Note that while the dynamic covalent catalysts are all chiral and the MBH reaction creates a new chiral center, onlyracemic iminoquinuclidine catalysts were used throughout this study. We are currently pursuing potential asymmetric catalysis and the study of the systemic effects of chirality with this compound class.

[34] M. S. Santos, J. T. M. Correia, A. P. L. Batista, M. T. Rodrigues, A. A. C. Braga, M. N. Eberlin, F. Coelho, in Lewis Base Catalysis in Organic Synthesis, Wiley-VCH Verlag GmbH \& Co. KGaA, 2016, pp. 191-232.

[35] R. E. Plata, D. A. Singleton, J. Am. Chem. Soc. 2015, 137, 3811-26.

[36] C. Lindner, Y. Liu, K. Karaghiosoff, B. Maryasin, H. Zipse, Chem. Eur. J. 2013, 19, 6429-6434.

[37] D. Cantillo, C. O. Kappe, J. Org. Chem. 2010, 75, 8615-8626.

[38] P. Buskens, J. Klankermayer, W. Leitner, J. Am. Chem. Soc. 2005, 127, 16762-16763.

[39] V. K. Aggarwal, S. Y. Fulford, G. C. Lloyd-Jones, Angew. Chem. Int. Ed. 2005, 44, 1706-1708.

[40] K. E. Price, S. J. Broadwater, B. J. Walker, D. T. McQuade, J. Org. Chem. 2005, 70, 3980-3987.

[41] Y. Fort, M. C. Berthe, P. Caubere, Tetrahedron 1992, 48, 6371-6384.

[42] M. L. Bode, P. T. Kaye, Tetrahedron Lett. 1991, 32, 5611-5614.

[43] P. Frei, R. Hevey, B. Ernst, Chem. Eur. J. 2019, 25, 60-73.

[44] Y. Zhang, M. Barboiu, Chem. Rev. 2016, 116, 809-34.

[45] M. Mondal, A. K. Hirsch, Chem. Soc. Rev. 2015, 44, 2455-88.

[46] Y. Jin, C. Yu, R. J. Denman, W. Zhang, Chem. Soc. Rev. 2013, 42, 6634-6654.

[47] Y. Wei, M. Shi, Chem. Rev. 2013, 113, 6659-6690.

[48] D. Basavaiah, G. Veeraraghavaiah, Chem. Soc. Rev. 2012, 41, 68-78. 
[49] M. Lafuente, J. Atcher, J. Solà, I. Alfonso, Chem. Eur. J. 2015, 21, 17002-17009.

[50] K. Severin, D. H. Lee, J. A. Martinez, M. Vieth, M. R. Ghadiri, Angew. Chem. Int. Ed. 1998, 37, 126-128.

[51] P. T. Kaye, M. A. Musa, X. W. Nocanda, R. S. Robinson, Org. Biomol. Chem. 2003, 1, 1133-1138.

[52] P. T. Kaye, R. S. Robinson, Synth. Commun. 1996, 26, 2085-2097.

[53] DABCO and quinuclidines, suchas those used throughout this study exhibit comparable catalytic activity for $\mathrm{MBH}$ reactions, andhence $\mathrm{DABCO}$ was used for convenience and to generate $1 \mathrm{H}$ NMR spectral data with less overlapping peaks.

[54] T. O. Olomola, R. Klein, M. R. Caira, P. T. Kaye, J. Org. Chem. 2016, 81, 109-120.

[55] N. Dominelli-Whiteley, J. J. Brown, K. B. Muchowska, I. K. Mati, C. Adam, T. A. Hubbard, A. Elmi, A. J. Brown, I. A. W. Bell, S. L. Cockroft, Angew. Chem. Int. Ed. 2017, 56, 7658-7662.

[56] A. Shokri, A. Abedin, A. Fattahi, S. R. Kass, J. Am. Chem. Soc. 2012, 134, 10646-10650.

[57] Formation of an off-cycle intermediate was also noticed during these tests, proposedto be the protonated conjugate between the acrylate and the iminoquinuclidine (Figures S2-S3). 